\title{
Impacts of reservoir boundaries and fracture dimensions on pressure behaviors and flow regimes of hydraulically fractured formations
}

\author{
Salam Al Rbeawi • D. Tiab
}

Received: 7 May 2013/Accepted: 5 July 2013/Published online: 20 July 2013

(C) The Author(s) 2013. This article is published with open access at Springerlink.com

\begin{abstract}
Hydraulic fracturing process is an important stimulation technique that has been widely used in conventional and unconventional oil and gas reservoirs. The technique involves creation of fracture or fracture system in porous medium to overcome wellbore damage, to improve oil and gas productivity in low-permeability reservoirs or to increase production in secondary recovery operations. This paper introduces a new technique for interpreting pressures behavior of a horizontal well with multiple hydraulic fractures. The well extends in multiboundary reservoirs having different configurations. The hydraulic fractures in this model can be longitudinal or transverse, vertical or inclined, symmetrical or asymmetrical. The fractures are propagated in isotropic or anisotropic formations and considered having different dimensions and different spacing. The study has shown that pressure responses and flow regimes are significantly influenced by both reservoir's boundaries and fractures' dimensions. Different flow regimes have been observed for different conditions. New flow regimes have been introduced in this study. The first one is the early radial flow regime which represents the radial flow around each fracture in the vertical plane resulted due to the partial vertical penetration of hydraulic fractures. The second one is the second linear flow regime which represents the linear flow toward each fractures in the vertical
\end{abstract}

S. Al Rbeawi ( $\square)$

Misan University, Amarah, Iraq

e-mail: slmjbr1964@gmail.com

D. Tiab

University of Oklahoma, Norman, USA plane normal to the wellbore resulted due to the long spacing between fractures. The third one is the third linear flow regime which represents the linear flow in the vertical plane parallel to the wellbore after the pressure pulse reaches the upper and lower impermeable boundaries.

Keywords Hydraulic fracturing - Horizontal wells . Reservoir simulation - Mathematical modeling - Pressure transit analysis - Reservoir characterization

\section{List of symbols}

$B$ Oil formation volume factor, RB/STB

$D \quad$ Spacing between fractures, $\mathrm{ft}$

$D_{\mathrm{D}} \quad$ Dimensionless spacing

$h \quad$ Formation height, $\mathrm{ft}$

$h_{\mathrm{f}} \quad$ Fracture height, $\mathrm{ft}$

$c_{\mathrm{t}} \quad$ Total compressibility, $\mathrm{psi}^{-1}$

$k_{x} \quad$ Permeability in the $X$-direction, md

$k_{y} \quad$ Permeability in the $Y$-direction, md

$k_{z} \quad$ Permeability in the $Z$-direction, md

$L_{\mathrm{D}} \quad$ Dimensionless wellbore length

$n \quad$ Number of hydraulic fractures

$P_{\mathrm{D}} \quad$ Dimensionless pressure

$q \quad$ Flow rate, STB/D

$t \quad$ Time, $\mathrm{h}$

$t_{\mathrm{D}} \quad$ Dimensionless time

$x_{\mathrm{f}} \quad$ Half fracture length, $\mathrm{ft}$

$x_{\mathrm{w}} \quad X$-Cartesian coordinates of the production point

$y_{\mathrm{w}} \quad Y$-Cartesian coordinates of the production point

$z_{\mathrm{w}} \quad Z$-Cartesian coordinates of the production point

$\phi \quad$ Porosity

$\mu \quad$ Viscosity, cp

$\eta \quad$ Diffusivity coefficient, $\mathrm{ft}^{2} / \mathrm{s}$ 


\section{Introduction}

Horizontal wells have become a common applied completion technology in the petroleum industry in the last couple decades. With a large reservoir contact area, horizontal wells can greatly improve well productivity and effectively handle problems with water cresting and gas coning. Recently, it is been found that drilling horizontal wells in thin and tight reservoirs with several hydraulic fractures is most advantageous and economically attractive completion option. Hydraulic fracturing is an important stimulation technique that has been widely used in conventional and unconventional oil and gas reservoirs all over the world. The technique involves creation of fracture or fracture system in porous medium to overcome wellbore damage, to improve oil and gas productivity in low-permeability reservoirs, or to increase production in secondary recovery operations. Depending on the stress orientation relative to the wellbore, the fractures may be transverse or longitudinal, vertical or inclined, and fully or partially penetrate the formations.

Even though hydraulic fracturing process has been a common application in the petroleum industry during the past two decades, the final output of this process is significantly affected by several factors. The successful process has to produce maximum actual production from the total reserve in the formation. Fracture dimensions (half fracture length, fracture width, and fracture height) are of great importance in the performance as are the orientation of the fractures as well as the rock and fluid properties. Typically, it is preferred that the fracture height be equal to the formation height, where fully penetrating fractures can be produced. Unfortunately, the fractures cannot always penetrate totally the formation where partially penetrating fractures may be produced. Partially penetrating hydraulic fractures are undesirable stimulation process due to the possibility of reducing the expected production rate of the fractured formation.

For hydraulically fractured horizontal wells, transient well testing is commonly used to determine reservoir parameters and to estimate well productivity. One of the big challenges is the three-dimensional nature of flow geometry in the formations. The radial flow symmetry no longer exists. Instead, several flow regimes may occur in and around the fractures. These flow regimes generally cannot be defined very well based on the test data. Moreover, many factors, such as vertical permeability or the vertical anisotropy, inclination angle from the vertical direction, the spacing between fractures, and the penetration ratio (the ratio of the fractures height to the formation height) can affect the transient pressure behavior.

Since 1972, several attempts have been done to model the pressure transient behavior for either horizontal or vertical wells, with or without hydraulic fractures. All these attempts were developed based on the using of the source solution and Green's function to solve unsteady-state flow problem in the reservoir which was presented by Gringarten and Ramey (1973). They used source function and Newman product method for solving transient flow problem. Although this approach is extremely powerful in solving two- and three-dimensional problem, it has some limitations such as incorporating the influence of storage and skin effects. The transient flow solutions have been extended to predict the behavior of the infinite conductivity vertical fracture in homogenous formations or in dual-porosity media. Cinco-Ley (1974) and Cinco-Ley et al. (1975) solved the problem for uniform flux and infinite conductivity inclined fracture in infinite slab reservoirs. They developed analytical models for the pressure behavior at the wellbore for a slanted hole and an inclined fracture associated with vertical wells. Cinco-Ley and Samaniego (1981) presented a method for the determination of the orientation of a fully penetrating vertical fracture by means of analysis of transient pressure data recorded at one active well and two observation wells due to production or injection at the active fractured well. Ozkan (1988) presented an extensive library of different solutions for diffusivity equation in terms of the Laplace transform variable. He considered a wide variety of wellbore configurations, different bounded systems, and homogeneous or double-porosity reservoirs.

Wright and Conant (1995) provided field examples where the hydraulic fractures reoriented due to production. Inclined fracture reorientation led to new inclination angles after refracturing. They introduced examples where the inclination angle has changed from $82^{\circ}$ to $45^{\circ}$. This was the result of the production depletion between the two fracturing treatments. This is clear evidence that production activities can affect the in situ stress state and thus change the direction of principle stresses. Even though great attentions were focused on the study of pressure transient analysis of hydraulically fractured wells, there are few studies about the effects of the partially penetrating fractures. Raghavan et al. (1978) were the first presented an analytical model that examines the effect of the fracture height on the pressure behavior of single vertical fracture. Their model was derived based on the solution technique presented by Gringarten and Ramey (1973). Rodriguez et al. (1984a, b) developed semi-analytical solution for the transient flow behavior of a reservoir with a well intersecting a partially penetrating single vertical fracture of both finite and infinite conductivity cases. The results of this study explained that the flow behavior of partially penetrating fracture during the early time period is equivalent to that of totally penetrating fracture. Alpheus and Tiab (2008) studied the effect of the partial penetrating infinite conductivity hydraulic fractures on the pressure behavior of horizontal well extending in naturally fractured formation. They stated that the duration of early linear flow regime is a function of the hydraulic fractures height. 
Raghavan et al. (1997) developed a mathematical model to discern the characteristic response of multiply fractured horizontal wells. Three significant flow periods have been observed based on their model: the early time period in which the system behaved like the one with $n$-layers, the intermediate time period in which the system reflected the interference between the fractures, and late time period in which the system behaved as a single fracture horizontal well with length equal the distance between the outermost fractures. Zerzar et al. (2003) combined the boundary element method and Laplace transformation to present a comprehensive solution for multiple vertical fractures horizontal wells. Seven flow regimes have been noticed: bilinear, first linear, elliptical, radial, pseudo-radial, second linear, and pseudo-steady state. Al-Kobaisi and Ozkan (2004) presented a hybrid numerical-analytical model for the pressure transient response of horizontal wells intercepted by a vertical fracture. Dinh and Tiab (2009a, b) solved the analytical model presented by Cinco-Ley (1974) for the pressure transient behavior caused by an inclined fracture associated with vertical wellbore. The model used the uniform flux and infinite conductivity fracture solution for different inclination angles from the vertical direction. Both type curve and TDS technique have been used to estimate the formation parameters such as permeability, skin factor, and fracture length.

\section{Mathematical models}

The analytical model for the pressure behavior of a horizontal well intersecting partially penetrating multiple hydraulic fractures can be derived based on the solution for the diffusivity equation in the porous media. The following facts would be important to be noticed:

- The flow from the reservoir to the wellbore sections between fractures is negligible as compared with the flow from the reservoir to the fracture plane.

- Fluid flows from the reservoir to the well through planar hydraulic fractures.

- A first approximation of the behavior of the system is the uniform flux fracture case. It is assumed that fluid enters the fractures at a uniform rate per unit area of the fracture face.

The following assumptions are important for the derivation of the model:

1. The reservoir is homogenous, having constant and uniform thickness with two impermeable layers at the top and bottom of the formation.

2. Constant porosity and permeability in each direction, but the formation is anisotropic.
3. Gravitational and frictional effects are negligible.

4. The well is extending in the midpoint of the formation height (symmetrical).

5. Single phase fluid of small and constant compressibility, constant viscosity, and formation volume factor, flows from the reservoir to the wellbore.

6. Reservoir pressure is initially constant.

$\left.P\right|_{t=0}=P_{i}$

7. The pressure at the upper and lower impermeable boundaries is assumed to be constant so that

$$
\begin{aligned}
& \left.\frac{\partial P}{\partial Z}\right|_{Z=0}=0, \\
& \left.\frac{\partial P}{\partial Z}\right|_{Z=h}=0 .
\end{aligned}
$$

In dimensionless form, the model for pressure response of a horizontal well, as shown in Fig. 1, intersected by multiple hydraulic fractures acting in finite reservoirs is (Al Rbeawi and Tiab 2012)

$$
\begin{aligned}
P_{\mathrm{D}}= & \frac{\pi x_{\mathrm{fD}} y_{\mathrm{fD}}}{2} \int_{0}^{t_{\mathrm{D}}}\left\{\left[1+\frac{4}{\pi x_{\mathrm{fD}}} \sum_{n=1}^{\infty} \frac{1}{n} \exp \left(-\frac{\pi^{2} n^{2} \tau_{\mathrm{D}} x_{\mathrm{fD}}^{2}}{4}\right)\right.\right. \\
& \left.\times \sin \left(\frac{n \pi x_{\mathrm{fD}}}{2}\right) \cos \left(n \pi \frac{x_{\mathrm{wD}}}{2}\right) \cos \left(\frac{n \pi x_{\mathrm{D}}}{2}\right)\right] \\
& \times\left[1+\frac{1}{N} \sum_{m=1}^{\infty} \sum_{N=0}^{\infty} \exp \left(-\frac{\pi^{2} m^{2} \tau_{\mathrm{D}} y_{\mathrm{fD}}^{2}}{4}\right)\right. \\
& \times\left(\cos \left(m \pi\left(\frac{y_{\mathrm{D}}-y_{\mathrm{wD}}-2 N D_{\mathrm{D}}}{2}\right)\right)\right. \\
+ & \left.\cos \left(m \pi\left(\frac{y_{\mathrm{D}}+y_{\mathrm{wD}}+2 N D_{\mathrm{D}}}{2}\right)\right)\right] \\
& \times\left[1+\frac{4}{\pi h_{\mathrm{fD}}} \sum_{l=1}^{\infty} \frac{1}{l} \exp \left(-\frac{l^{2} \pi^{2} \tau_{\mathrm{D}}}{h_{x \mathrm{fD}}^{2}}\right) \sin \left(l \pi \frac{h_{\mathrm{fD}}}{2}\right)\right. \\
& \left.\times \cos \left(l \pi z_{\mathrm{wD}}\right) \cos \left(l \pi z_{\mathrm{wD}}\right)\right] \mathrm{d} \tau_{\mathrm{D}},
\end{aligned}
$$

where:

$$
\begin{aligned}
& x_{\mathrm{D}}=\frac{x}{x_{\mathrm{e}}} \\
& x_{\mathrm{fD}}=\frac{x_{\mathrm{f}}}{x_{\mathrm{e}}} \\
& x_{\mathrm{wD}}=\frac{x_{\mathrm{w}}}{x_{\mathrm{e}}} \\
& y_{\mathrm{D}}=\frac{y}{y_{\mathrm{e}}} \\
& y_{\mathrm{fD}}=\frac{x_{\mathrm{f}}}{y_{\mathrm{e}}} \sqrt{\frac{k_{y}}{k_{x}}}
\end{aligned}
$$




$$
\begin{aligned}
& y_{\mathrm{wD}}=\frac{y_{\mathrm{f}}}{y_{\mathrm{e}}} \\
& h_{x \mathrm{D}}=\frac{h}{x_{\mathrm{f}}} \sqrt{\frac{k_{x}}{k_{z}}} \\
& h_{\mathrm{fD}}=\frac{h_{\mathrm{f}}}{h} \\
& z_{\mathrm{wD}}=\frac{z_{\mathrm{w}}}{h} \\
& z_{\mathrm{D}}=\frac{z}{h} \\
& t_{\mathrm{D}}=\frac{k_{x} t}{\phi \mu c_{t} x_{\mathrm{f}}^{2}}=\frac{\eta_{x} t}{x_{\mathrm{f}}^{2}}, \text { where } \eta_{x}=\frac{k_{x}}{\phi \mu c_{t}} \\
& P_{\mathrm{D}}=\frac{2 \pi \sqrt{k_{x} k_{y}} h P\left(x_{m}, y_{m}, z_{m}, t, x_{\mathrm{f}}, h_{\mathrm{f}}, h\right)}{q \mu} \\
& D_{\mathrm{D}}=\frac{D}{x_{\mathrm{f}}} \sqrt{\frac{k_{x}}{k_{y}}} .
\end{aligned}
$$

\section{Pressure behavior}

Reservoir boundaries, fracture dimensions, vertical penetration of hydraulic fractures, and horizontal penetration of the wellbore to the total length of the reservoirs are four different parameters that have significant impact on pressure behaviors and flow regimes of hydraulically fractured horizontal wells. The effects of the boundaries and the horizontal penetration concentrate at the late time of production when pseudo-steady state and pseudo-radial flow are the expected flow regimes. However, the effects of the fracture dimensions and the vertical penetration concentrate at early time of production when early linear flow is the expected flow regime.

\section{Reservoir boundaries}

Pressure behavior of hydraulically fractured horizontal wells acting in finite reservoir is influenced by reservoir boundary in the horizontal plane. This influence can be noticed in the late time behavior when pseudo-radial flow or pseudo-steady-state flow is reached. The impact of the reservoir boundary on the pressure behavior depends on the drainage area, i.e., length and width of the reservoir and the length of the horizontal wellbore. For long and wide reservoir, there is enough time for pseudo-radial flow to develop and the pseudo-steady-state flow may need long time to be reached. For short and narrow reservoirs, pseudo-radial flow cannot be developed and the pseudosteady-state flow appears after short production time. The penetration ratio of the horizontal well in the horizontal plane (the ratio of the horizontal wellbore length to the reservoir length) affects significantly the response of the pressure and the type of the flow regimes expected to develop during early and late time of production. The horizontal penetration ratio can be written as

$L_{\mathrm{D}}=\frac{L_{\mathrm{w}}}{y_{\mathrm{e}}}$,

where $L_{\mathrm{w}}$ is the half-length of the horizontal wellbore.

Small horizontal penetration ratio $L_{\mathrm{D}}=0.1$

For small penetration ratio in the horizontal plane, three different pressure behaviors are expected to develop depending on the drainage area. Figures 2, 3, 4, and 5 show the pressure behaviors and flow regimes for different numbers of hydraulic fractures. The following classifications can be inferred for small horizontal penetration ratio:

- For small drainage area, i.e. short and narrow reservoirs, $1 \leq y_{\mathrm{fD}} \leq 1 / 4,1 \leq x_{\mathrm{fD}} \leq 1 / 4$. Because of the short spacing between fractures, intermediate radial flow regime which represents the radial flow toward each fracture from nearby drainage area cannot be observed. In addition, the small drainage area means that the pressure pulse reaches the boundary after short production time. Therefore, there is no enough time for the pseudo-radial flow to fully develop. The dominated flow regimes in this case are the early linear flow which
Fig. 1 Hydraulically fractured well in finite reservoir

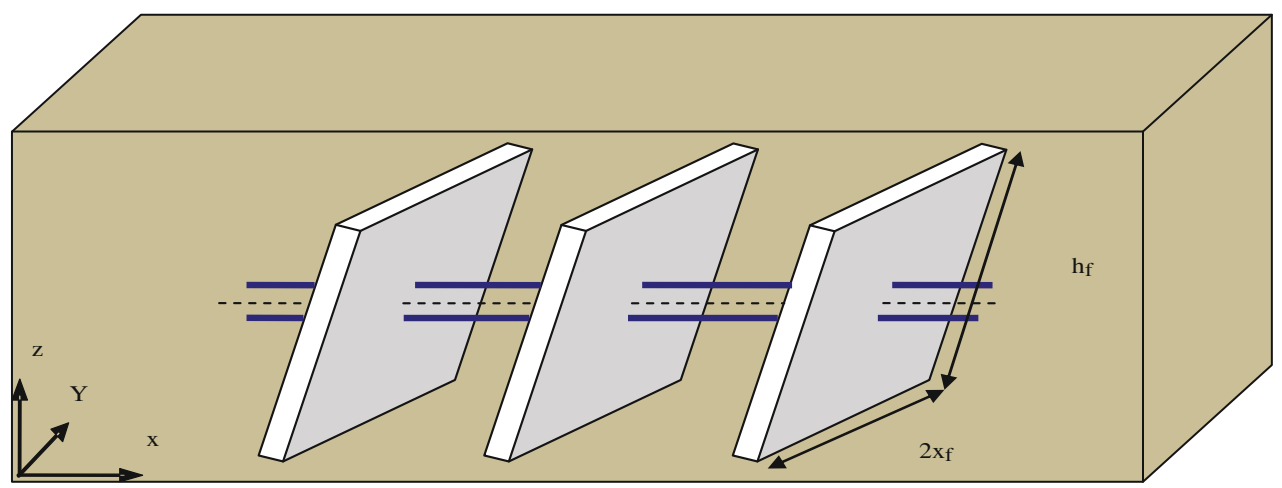


Fig. 2 Pressure behavior of two hydraulic fractures
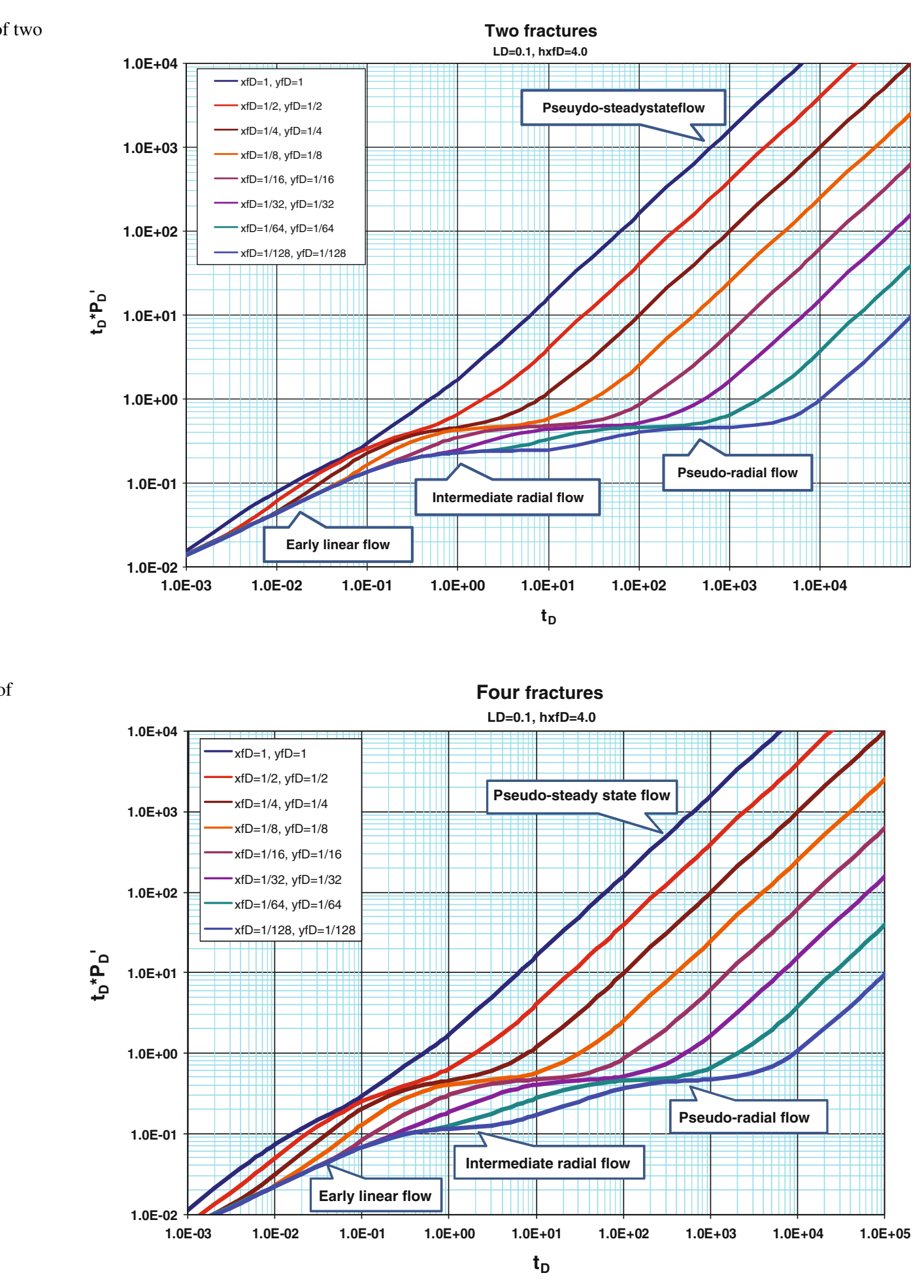

Four fractures
Fig. 3 Pressure behavior of four hydraulic fractures represents the flow from the drainage areas between fractures toward them and the pseudo-steady-state flow which represents the effect of the reservoirs boundary.

- For moderate drainage area, $1 / 8<y_{\mathrm{fD}}<1 / 16,1 / 8$ $<x_{\mathrm{fD}}<1 / 16$. Intermediate radial flow regime cannot be observed because of the short spacing between fractures, especially for large number of fractures.
However, pseudo-radial flow which represents the radial flow toward all fractures from the far drainage area may develop. The dominated flow regimes in this case are early linear, pseudo-radial, and pseudo-steady-state flow.

- For big drainage area, i.e., long and wide reservoirs, $1 / 16 \leq y_{\mathrm{fD}}, 1 / 16 \leq x_{\mathrm{fD}}$. Because of the long spacing between fractures, intermediate radial flow regime can 
Fig. 4 Pressure behavior of two hydraulic fractures

Fig. 5 Pressure behavior of four hydraulic fractures
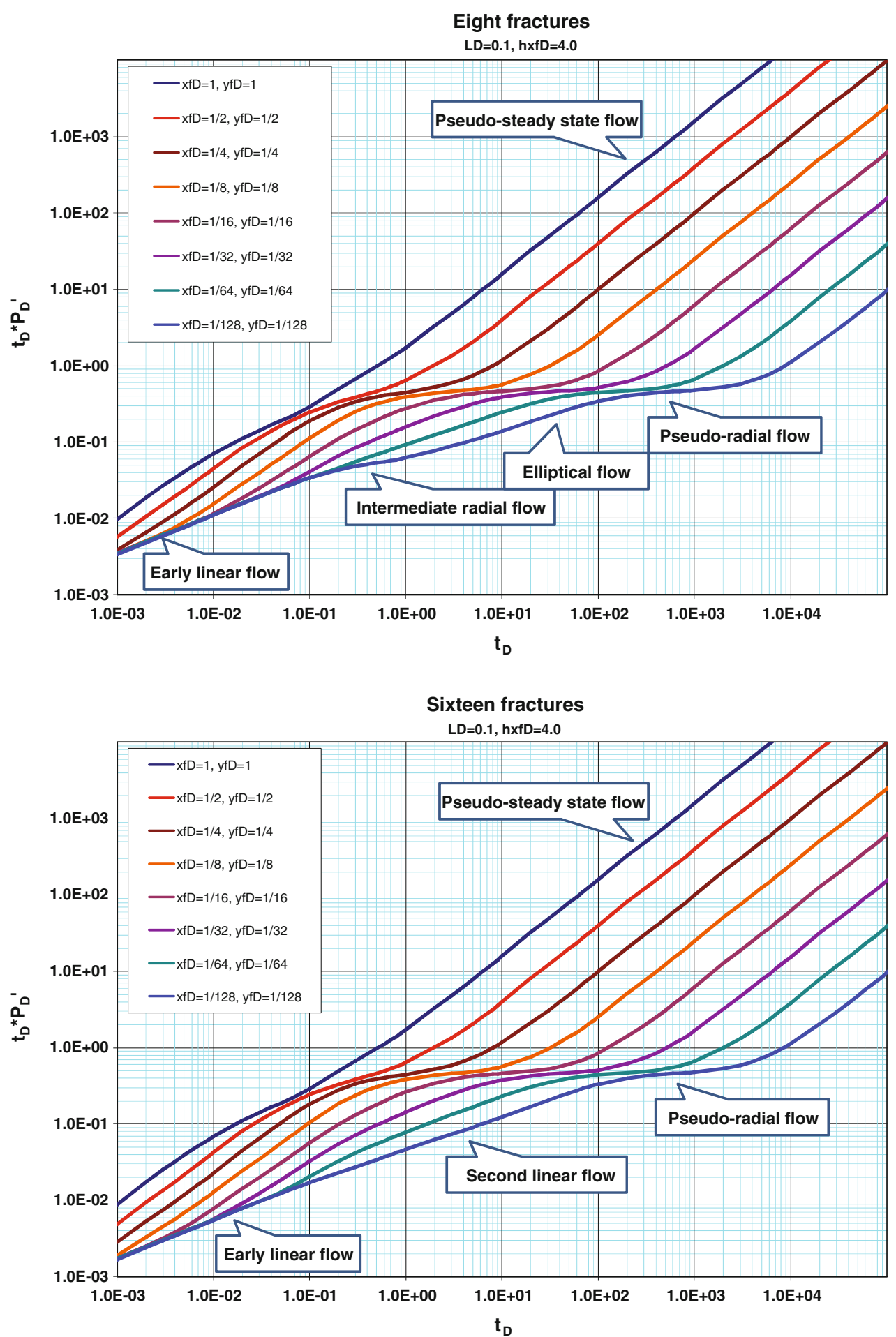

be developed after early linear flow. However, this flow regime cannot be observed for large number of fractures. In addition, pseudo-radial flow can be developed also because of the long and wide reservoirs. Elliptical flow regime may develop after early radial flow and before pseudo-radial flow. The dominated flow regimes in this case are early linear, intermediate radial, pseudo-radial, elliptical, and pseudo-steady-state flow.
Moderate horizontal penetration ratio $L_{\mathrm{D}}=0.5$

For moderate penetration ratio in the horizontal plane, pseudo-radial flow is not expected to develop because of the short distance between the outermost fractures and the boundary normal to the wellbore. However, channel flow which represents linear flow in one horizontal direction can be noticed for the case of big drainage areas when the 
pressure pulse reaches the boundary normal to the horizontal wellbore. Figures 6, 7, 8, and 9 show the pressure behaviors and flow regimes for different numbers of hydraulic fractures. Two different pressure behaviors are expected to develop depending on the drainage area for this penetration ratio.

- For small drainage area, i.e., short and narrow reservoirs, $1 \leq y_{\mathrm{fD}} \leq 1 / 8,1 \leq x_{\mathrm{fD}} \leq 1 / 8$ Because of the short spacing between fractures, intermediate radial flow regime cannot be observed. In addition, moderate penetration ratio and small drainage area mean that the pressure pulse reaches the boundary after short production time. Therefore, there is no enough time for the pseudo-radial flow to develop. The dominated flow regimes in this case are the early linear flow and the pseudo-steady-state flow.

- For moderate and big drainage area, $1 / 8<y_{\mathrm{fD}}$, $1 / 8<x_{\mathrm{fD}}$ Intermediate radial flow regime can be observed because of the long spacing between fractures. Channel flow is expected to develop after early intermediate flow, especially for large number of fractures. The dominated flow regimes in this case are early linear, intermediate radial, channel, and pseudosteady-state flow.

\section{Fully horizontal penetration $L_{\mathrm{D}}=0.1$}

For full penetration in the horizontal plane, pseudo-radial flow is not expected to develop because there is no spacing between the outermost fractures and the boundary normal to the wellbore. Similar to the moderate penetration ratio, channel flow can be noticed for the case of big drainage areas when the pressure pulse reaches the boundary normal to the horizontal wellbore. Figures 10, 11, 12, and 13 show the pressure behaviors and flow regimes for different numbers of hydraulic fractures. Two different pressure behaviors are expected to develop depending on the drainage area for this penetration ratio.

- For small drainage area, i.e., short and narrow reservoirs, $1 \leq y_{\mathrm{fD}} \leq 1 / 8,1 \leq x_{\mathrm{fD}} \leq 1 / 8$ Because of the short spacing between fractures, intermediate radial flow regime cannot be observed. In addition, full penetration and small drainage area mean that the pressure pulse reaches the boundary after short production time. Therefore, there is no enough time for the pseudoradial flow to develop. The dominated flow regimes in this case are the early linear flow and the pseudosteady-state flow.

- For moderate and big drainage area, $1 / 8<y_{\mathrm{fD}}$, $1 / 8<x_{\mathrm{fD}}$ early-radial flow regime can be observed because of the long spacing between fractures. Channel flow is expected to develop after intermediate radial flow for large number of fractures. The dominated flow regimes in this case are early linear, early-radial, channel, and pseudo-steady-state flow.

For rectangular drainage area, channel flow may develop for small horizontal penetration ratio after early linear or intermediate radial flow as shown in Fig. 14. For large
Fig. 6 Pressure behavior of two hydraulic fractures

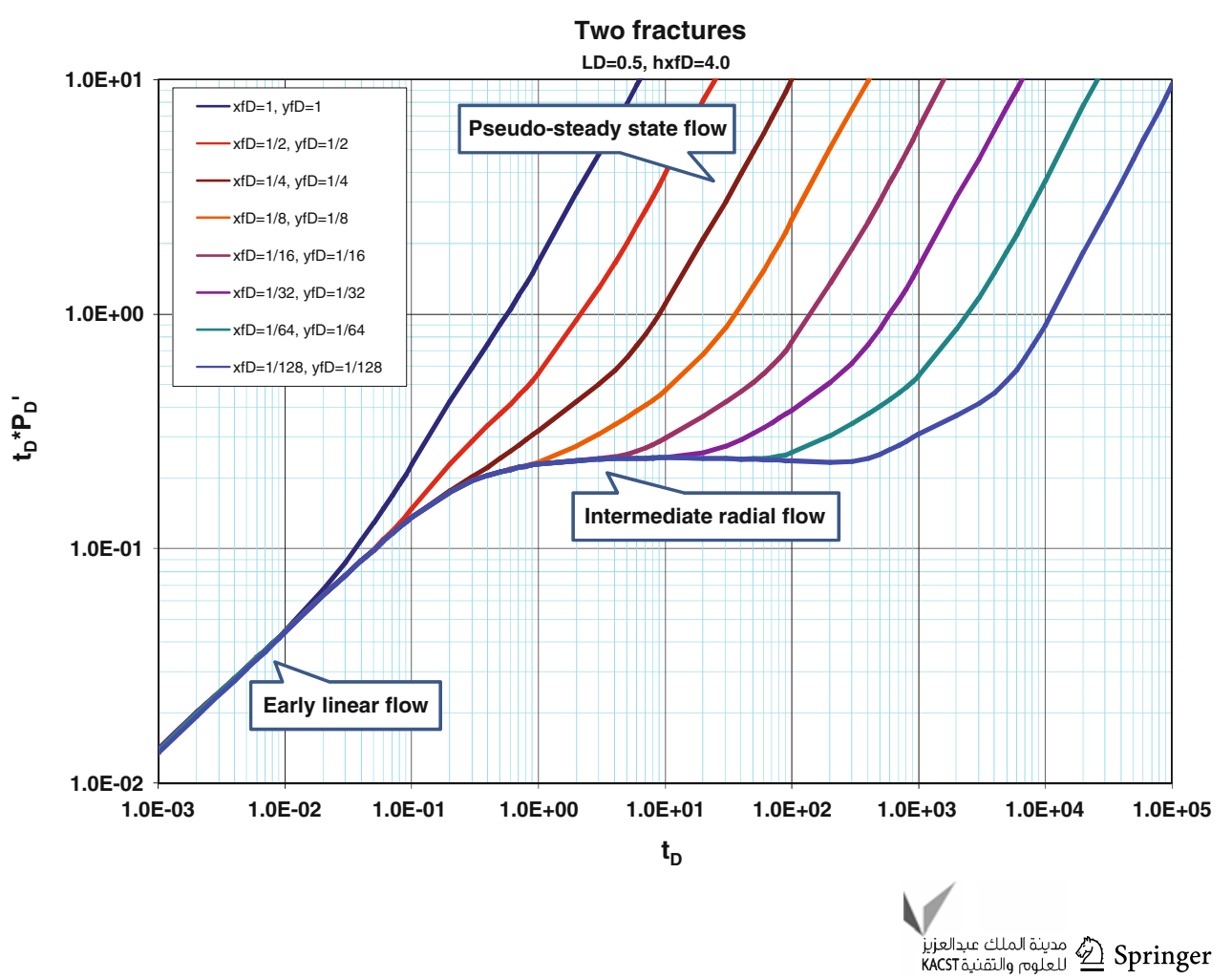


Fig. 7 Pressure behavior of four hydraulic fractures

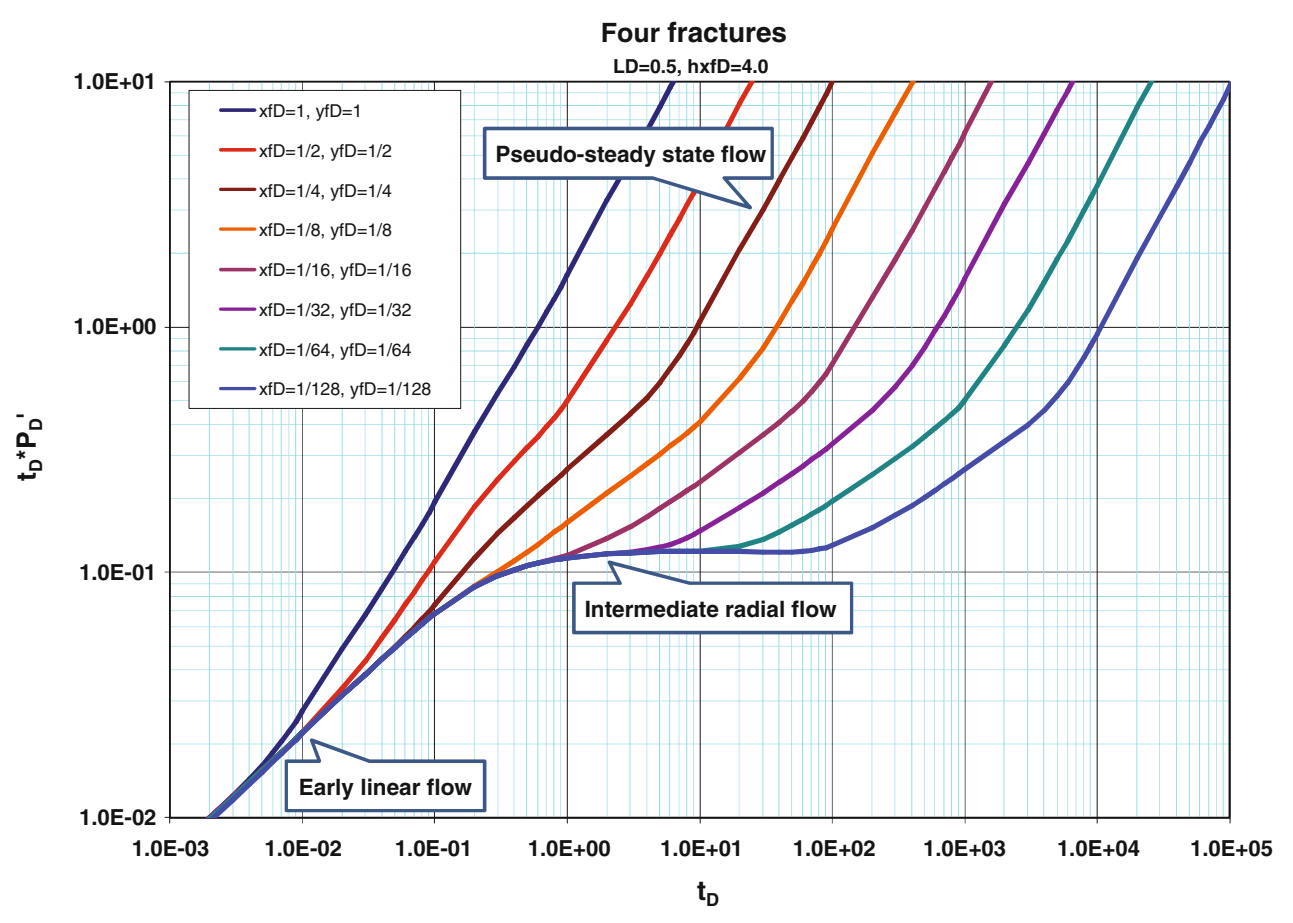

Fig. 8 Pressure behavior of two hydraulic fractures

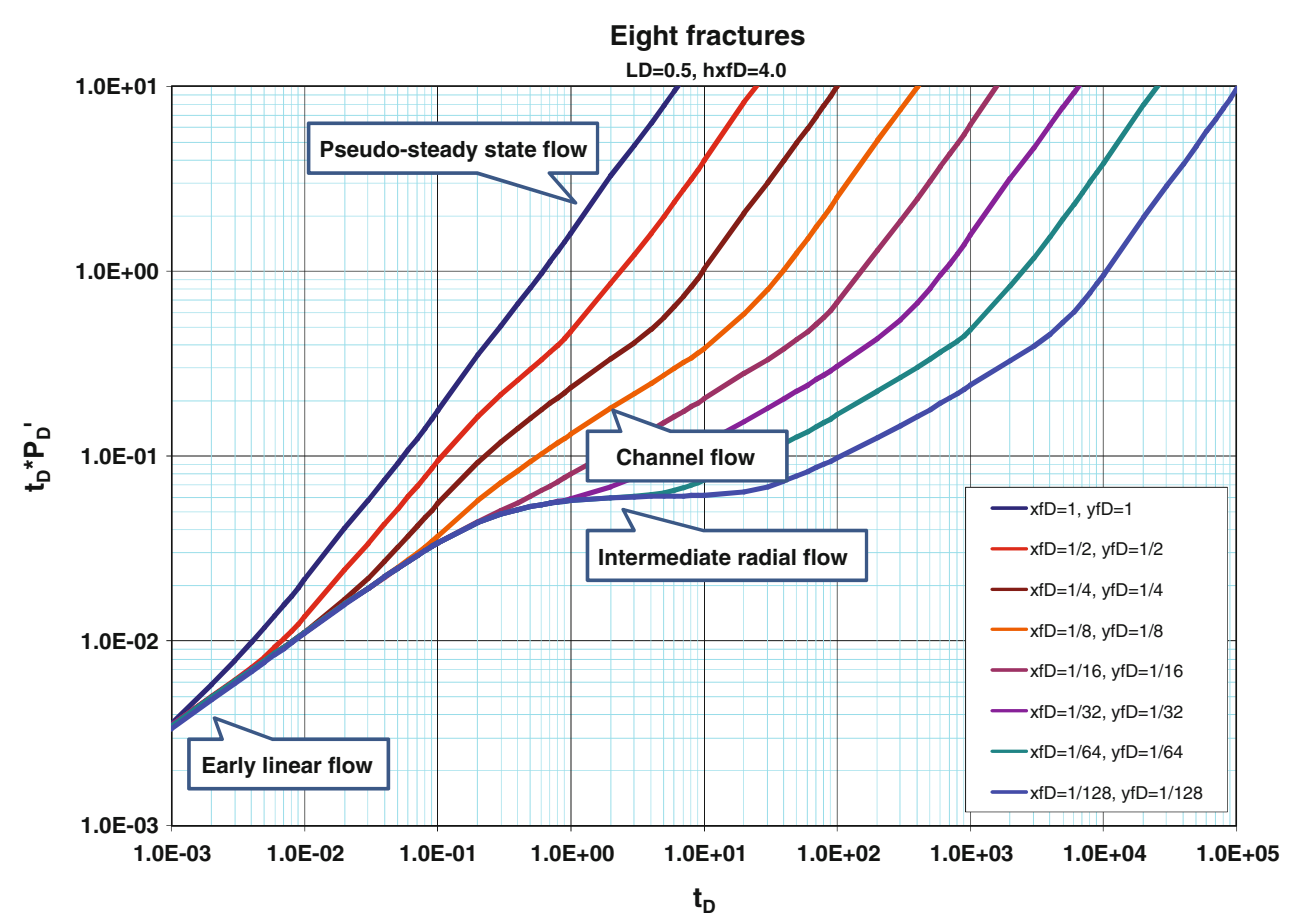

horizontal penetration ratio, channel flow may develop only for long reservoirs as shown in Fig. 15.

Fracture dimensions

Pressure behaviors and flow regimes are affected by the fracture dimensions (length and height). These effects are not similar for all numbers of hydraulic fractures and all fracture lengths and heights. Fracture length does not affect the flow regimes, but it affects the pressure behaviors. However, fracture height has significant impact on both pressure behaviors and flow regimes.

The impact of fracture half-length on pressure behaviors and flow regimes can be seen in Figs. 16 and 17. It is easy to recognize that the flow regimes do not change with the change in the fracture half-length for all numbers of fractures. 
Fig. 9 Pressure behavior of four hydraulic fractures
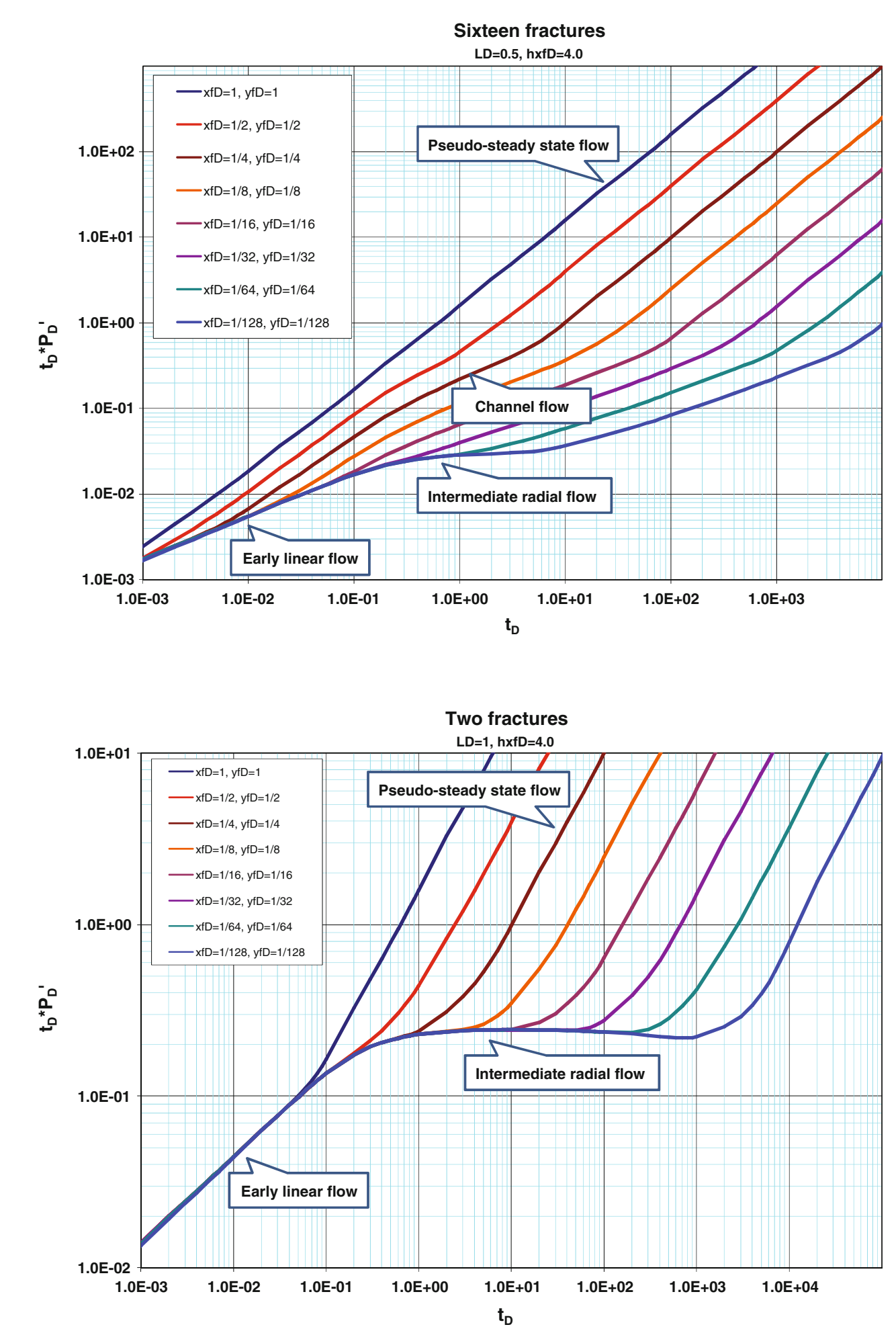

Fig. 10 Pressure behavior of two hydraulic fractures
1. For a small number of hydraulic fractures $(<10)$ as shown in Fig. 16, linear and pseudo-radial flow are the two dominated flow regimes for fully penetrating fractures.

2. For a large number of hydraulic fractures $(>10)$ such as in Fig. 17, linear and pseudo-radial flow are the dominated flow regimes for fully penetrating fractures. Third linear flow regime may develop for short spacing between fracture. Third linear flow represents the linear flow in the $Y Z$ plane after the pressure pulse reaches the upper and lower impermeable boundaries. 
Fig. 11 Pressure behavior of four hydraulic fractures
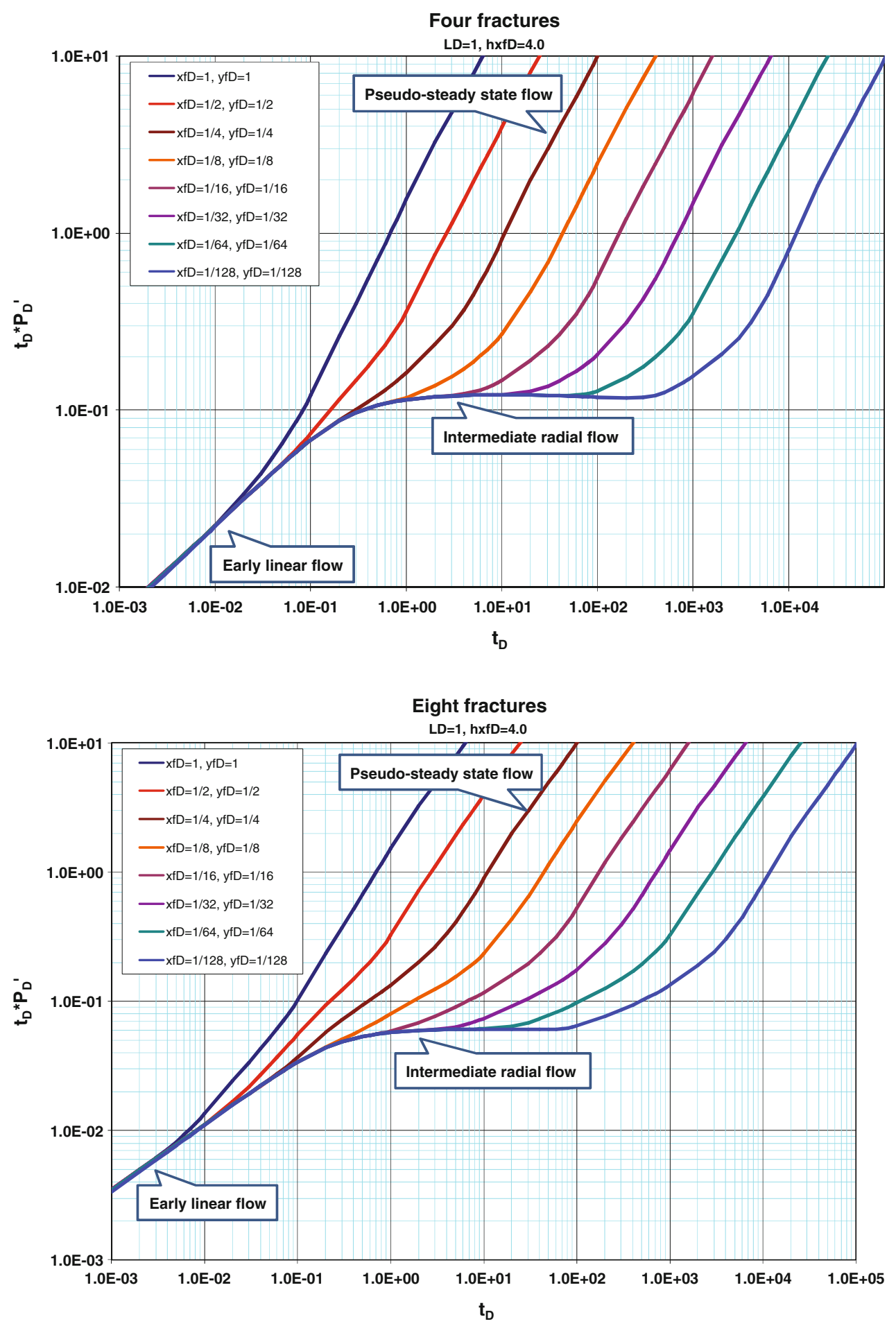

Fig. 12 Pressure behavior of two hydraulic fractures
Spacing between fractures has significant impact on both pressure behaviors and flow regimes. The drainage area around each fracture increases as the spacing between fractures increases. Therefore, when this area is big enough, intermediate radial flow regime is observed. This flow regime represents the radial flow toward each fracture in the $X Y$ plane. Figure 19 shows the flow regimes for long spacing between four fractures. For short spacing between fractures, third linear flow may develop before pseudoradial flow as shown in Fig. 18.

Fracture height: penetration ratio

Fracture height has the great influence on pressure behaviors and flow regimes of hydraulically fractured horizontal wells. Hydraulic fractures with full penetration in the 
Fig. 13 Pressure behavior of four hydraulic fractures
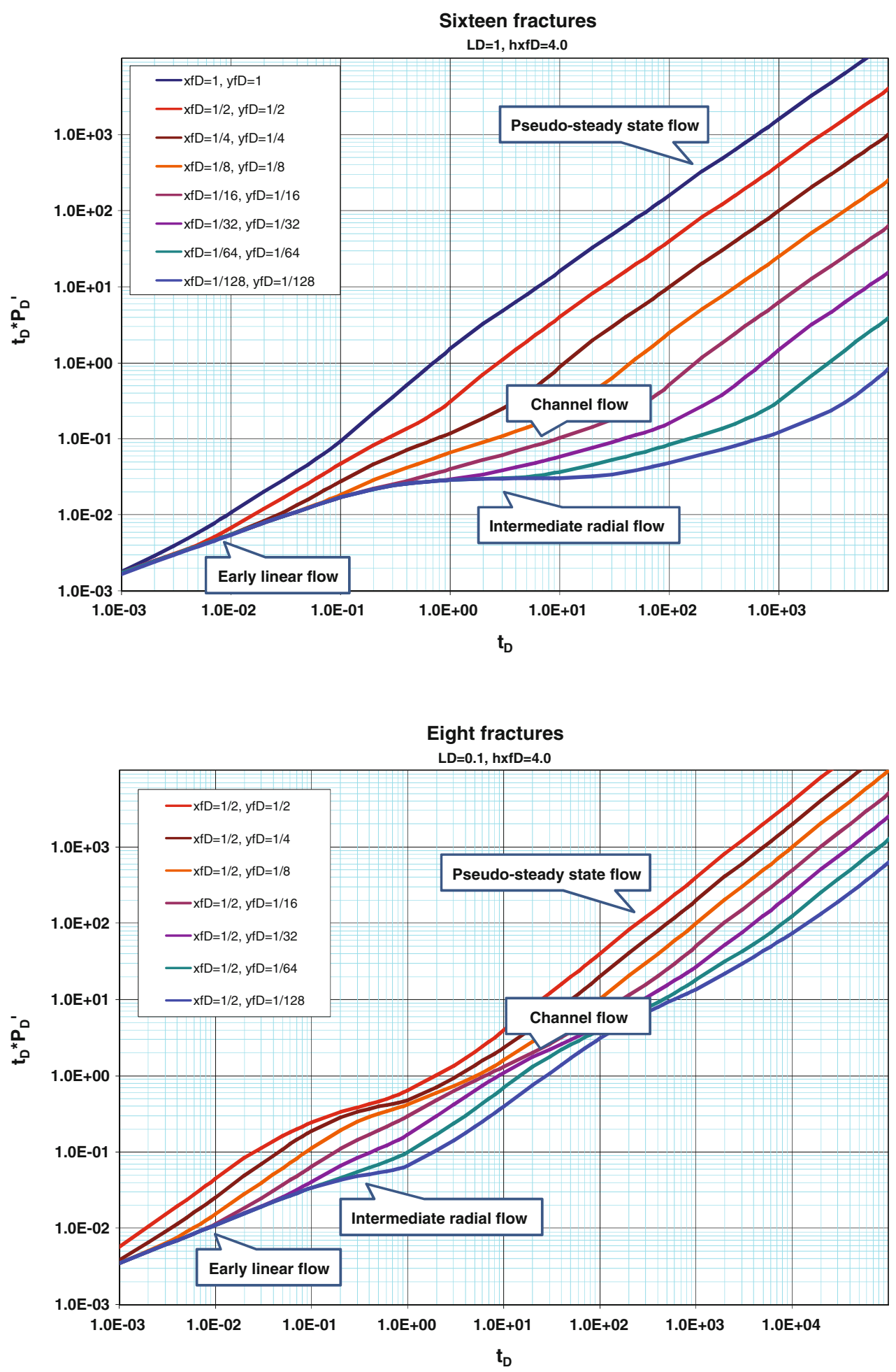

Fig. 14 Pressure behavior of eight hydraulic fractures in rectangular reservoirs vertical direction means successful fracturing process. As the vertical penetration ratio (the ratio of the fracture's height to the formation's height) decreases, new flow regimes may develop. The first of these new regimes is the second linear flow. This regime represents the flow toward the fractures in the $X Z$ plane after the pressure behavior is affected by the upper and lower boundary. The second regime is the early radial flow that represents the radial flow in the $Y Z$ plane toward the fracture before the boundaries are reached. These flow regimes are expected to develop in addition to the early linear (first linear) flow, intermediate radial (early radial for fully penetrating fractures), third linear, elliptical flow, and pseudo-radial flow. Two pressure responses can be classified based on the penetrating ratio. 
Fig. 15 Pressure behavior of eight hydraulic fractures in rectangular reservoirs

Fig. 16 Effect of fracture length for two hydraulic fractures
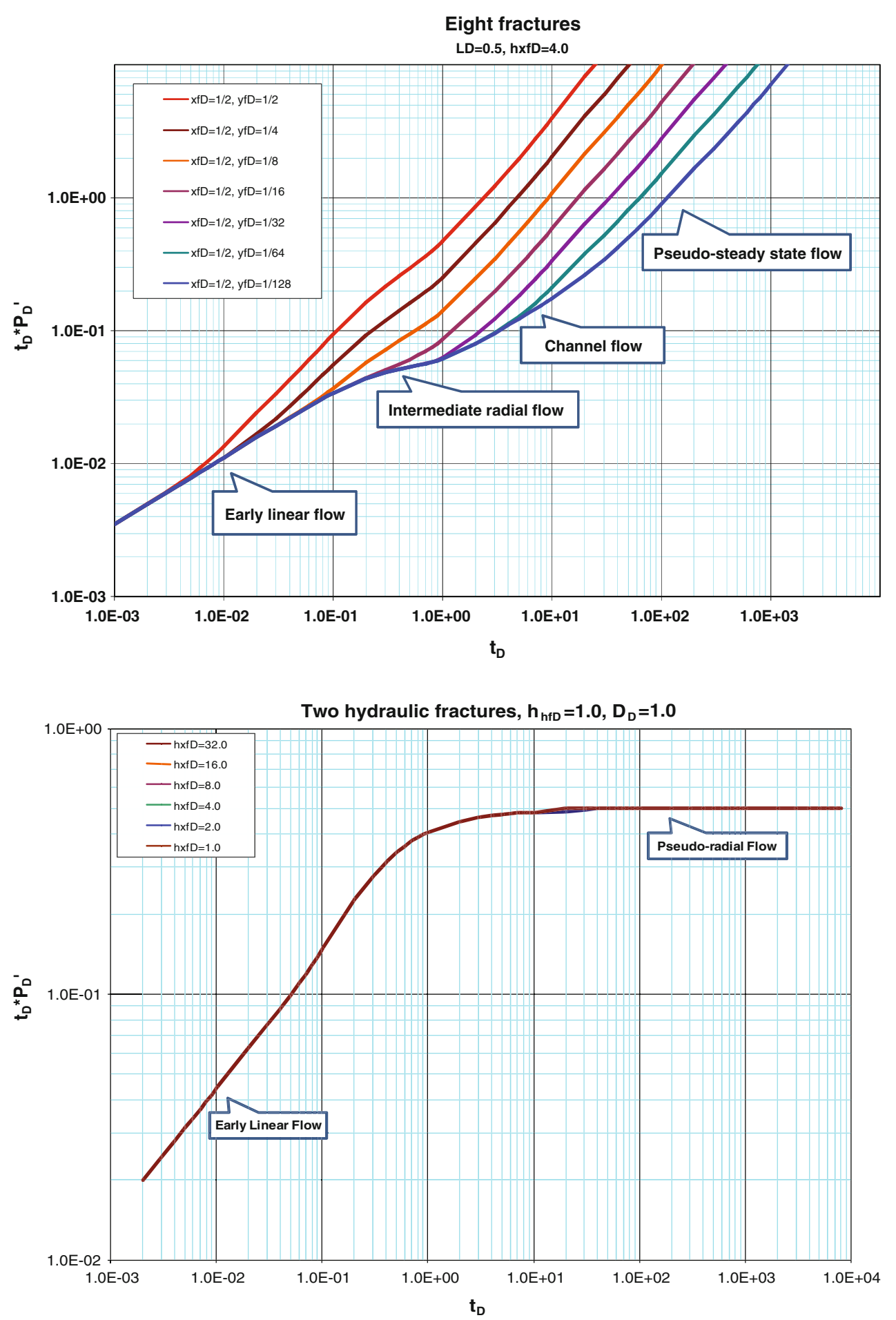

Large penetration ratio $\left(h_{h f D}>0.5\right)$

Because of the penetration ratio, the pressure behavior in this case tends to be similar to the fully penetrating fractures where other factors such as the number of fractures, spacing between them, and fracture dimensions have the main influences.
Short half fracture length $\left(h_{x f D}<10\right)$

1. For a small number of hydraulic fractures $(<10)$, first linear, transition, second linear, transition, and pseudoradial flow are observed as shown in Fig. 20.

2. For a large number of hydraulic fractures $(>10)$, first linear, transition, second linear, third linear, transition, and pseudo-radial flow regimes are observed such as in Fig. 21. 
Fig. 17 Effect of fracture length for sixteen hydraulic fractures
Fig. 18 Effects of short spacing for four hydraulic fractures
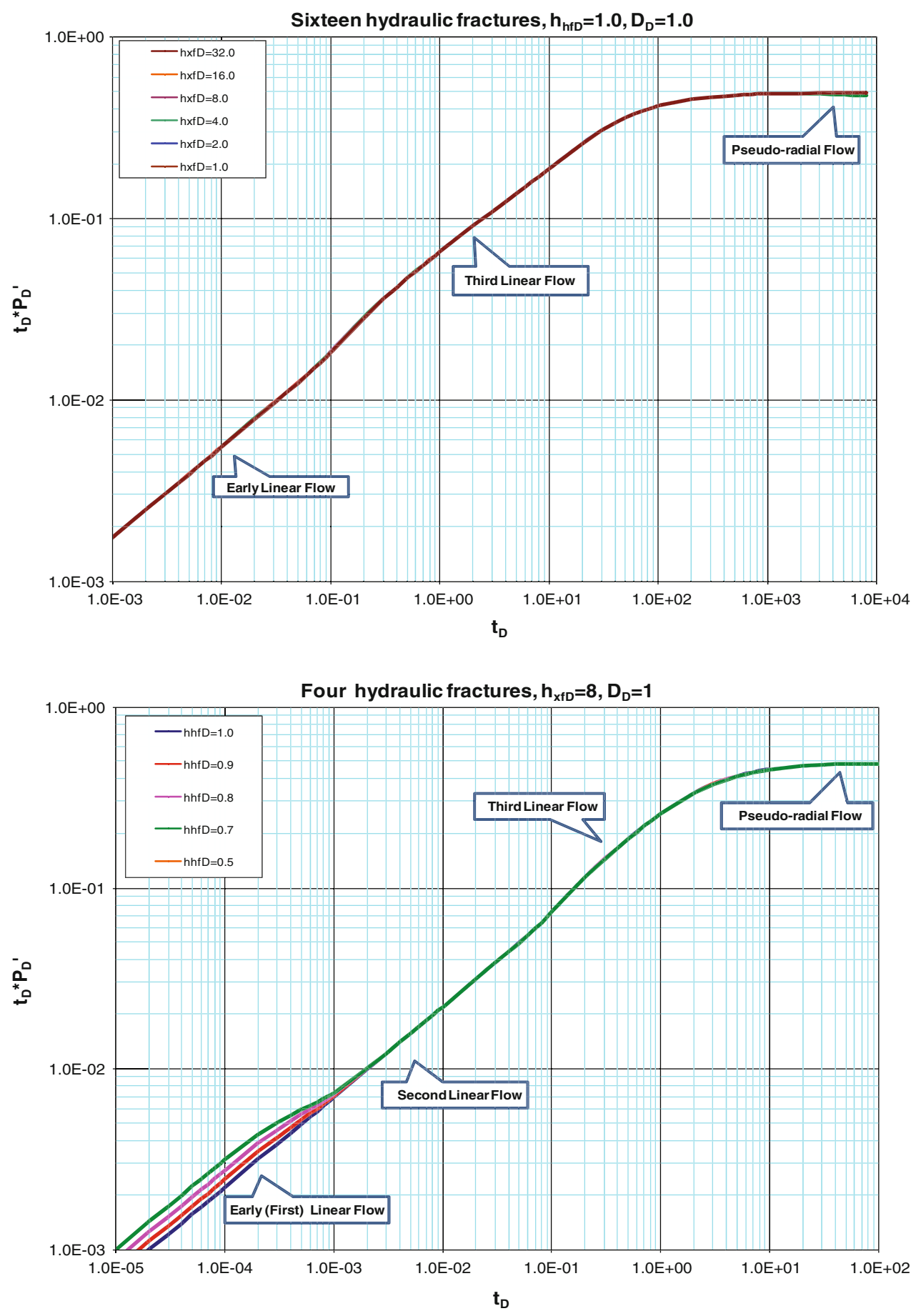

Long half fracture length $\left(h_{x f D}>10\right)$

1. For a small number of hydraulic fractures $(<10)$, first linear, transition, second linear, transition and pseudoradial flow regimes are observed as shown in Fig. 22.

2. For a large number of hydraulic fractures $(>10)$, first linear flow is not observed. Therefore, second linear, third linear, transition and pseudo-radial flow regimes are the only flow regimes that are observed such as in Fig. 23.
Small penetration ratio $\left(h_{h f D}<0.5\right)$

Because of the small penetration ratio, the pressure behavior at early time tends to develop a new early radial flow regime where the flow of fluid takes place in the $Y Z$ plane.

Short half fracture length $\left(h_{x f D}<10\right)$

1. For a small number of hydraulic fractures $(<10)$, first linear, transition, early radial, transition, and 
Fig. 19 Effects of long spacing for four hydraulic fractures
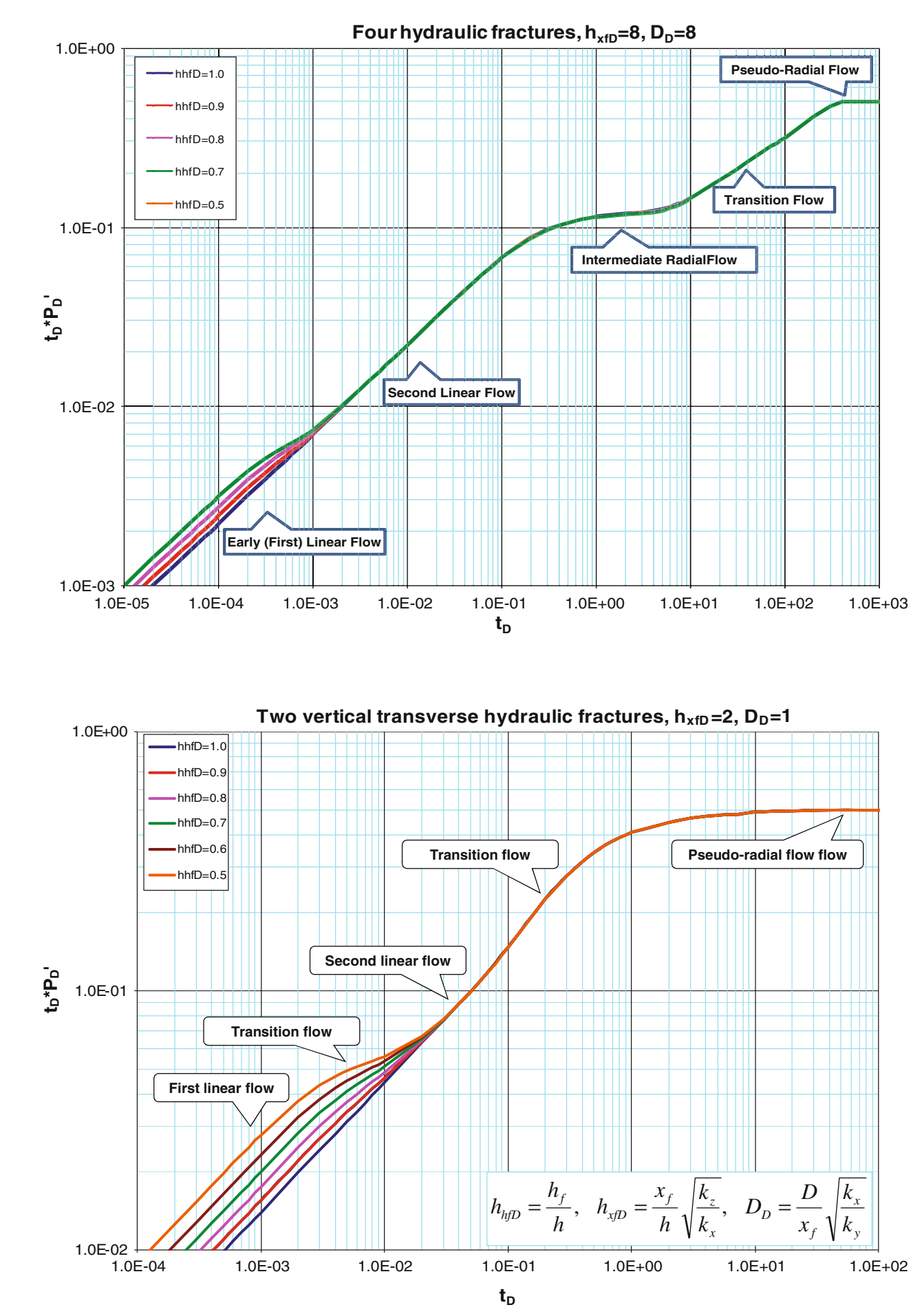

Fig. 20 Pressure behavior of two partially penetrating hydraulic fractures pseudo-radial flow regimes are observed as shown in Fig. 24.

2. For a large number of hydraulic fractures $(>10)$, first linear, early radial, second linear, third linear, transition, and pseudo-radial flow regimes are observed such as in Fig. 25.
Long half fracture length $\left(h_{x f D}>10\right)$

1. For a small number of hydraulic fractures $(<10)$, first linear flow cannot be observed. Early radial, second linear, transition, and pseudo-radial flow regimes are observed as shown in Fig. 26. The behavior in this case 
Fig. 21 Pressure behavior of sixteen partially penetrating hydraulic fractures
Fig. 22 Pressure behavior of two partially penetrating hydraulic fractures
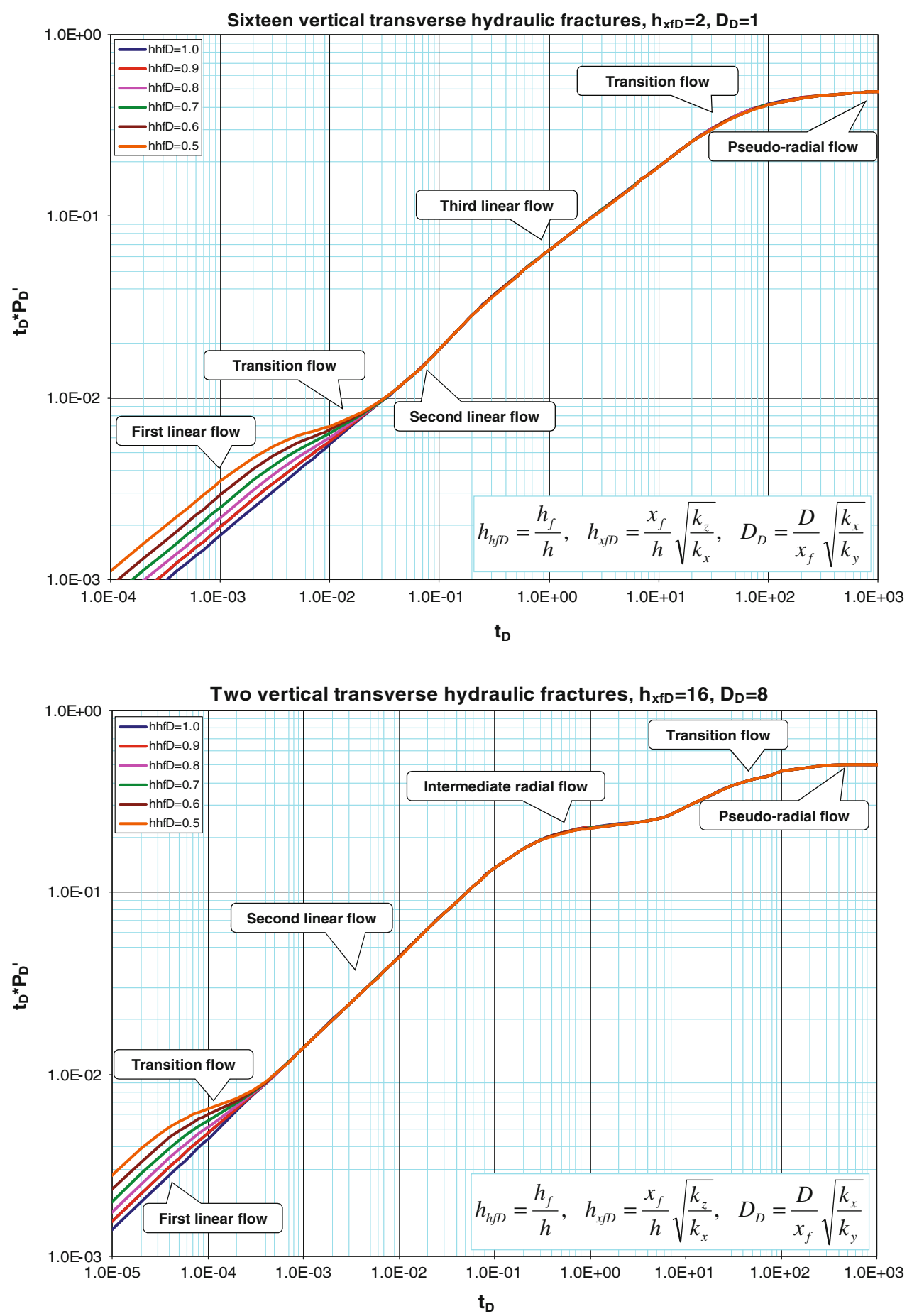

is similar to the horizontal wells with short to moderate wellbore length.

2. For a large number of hydraulic fractures $(>10)$, neither first linear flow nor early radial flow can be observed. Second linear, third linear, transition, and pseudo-radial flow are the only flow regimes that are observed such as in Fig. 27. The behavior in this case is similar to a single vertical hydraulic fracture.

\section{Flow regimes}

Early (first) linear flow regime

At early time, reservoir fluid flows linearly and directly from the formation to the individual fractures in the $X Z$ plane as shown in Fig. 28. Each fracture behaves independently of the others. The flow regime is represented by straight line with a slope of $(0.5)$ in the $\log -\log$ plots for

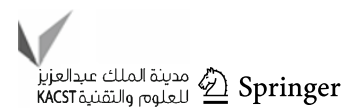


Fig. 23 Pressure behavior of sixteen partially penetrating hydraulic fractures
Fig. 24 Pressure behavior of two partially penetrating hydraulic fractures
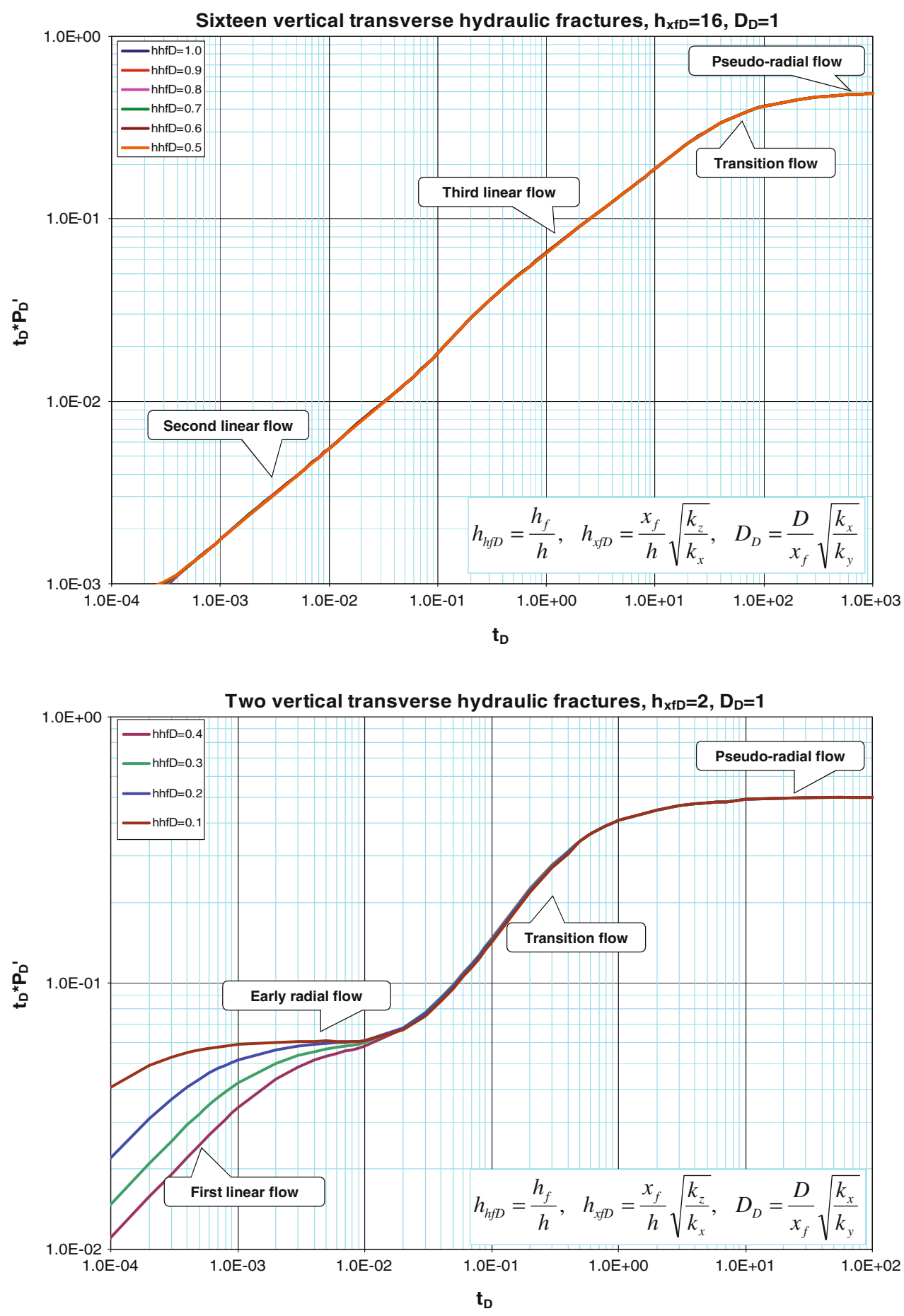

both dimensionless pressure and pressure derivative with dimensionless time. The governing equations for linear flow regime are

$\left(P_{\mathrm{D}}\right)_{\mathrm{FLF}}=\frac{\sqrt{\pi t_{\mathrm{D}}}}{n h_{\mathrm{hfD}}}$,

$\left(t_{\mathrm{D}} \times P_{\mathrm{D}}^{\prime}\right)_{\mathrm{FLF}}=\frac{\sqrt{\pi t_{\mathrm{D}}}}{2 n h_{\mathrm{hfD}}}$.
Early radial flow regime

Early radial flow regime represents the radial flow around each fracture in the $Y Z$ plane. Typically, this flow is observed when the penetration ratio is small $\left(h_{\mathrm{hfD}}<0.5\right)$ and the spacing between fractures is long $\left(D_{\mathrm{D}}>5\right)$. In this flow, reservoir fluids flow radially in $Y Z$ plane toward each individual fractures such as shown in Fig. 29. The governing equation for this flow is 
Fig. 25 Pressure behavior of sixteen partially penetrating hydraulic fractures
Fig. 26 Pressure behavior of two partially penetrating hydraulic fractures
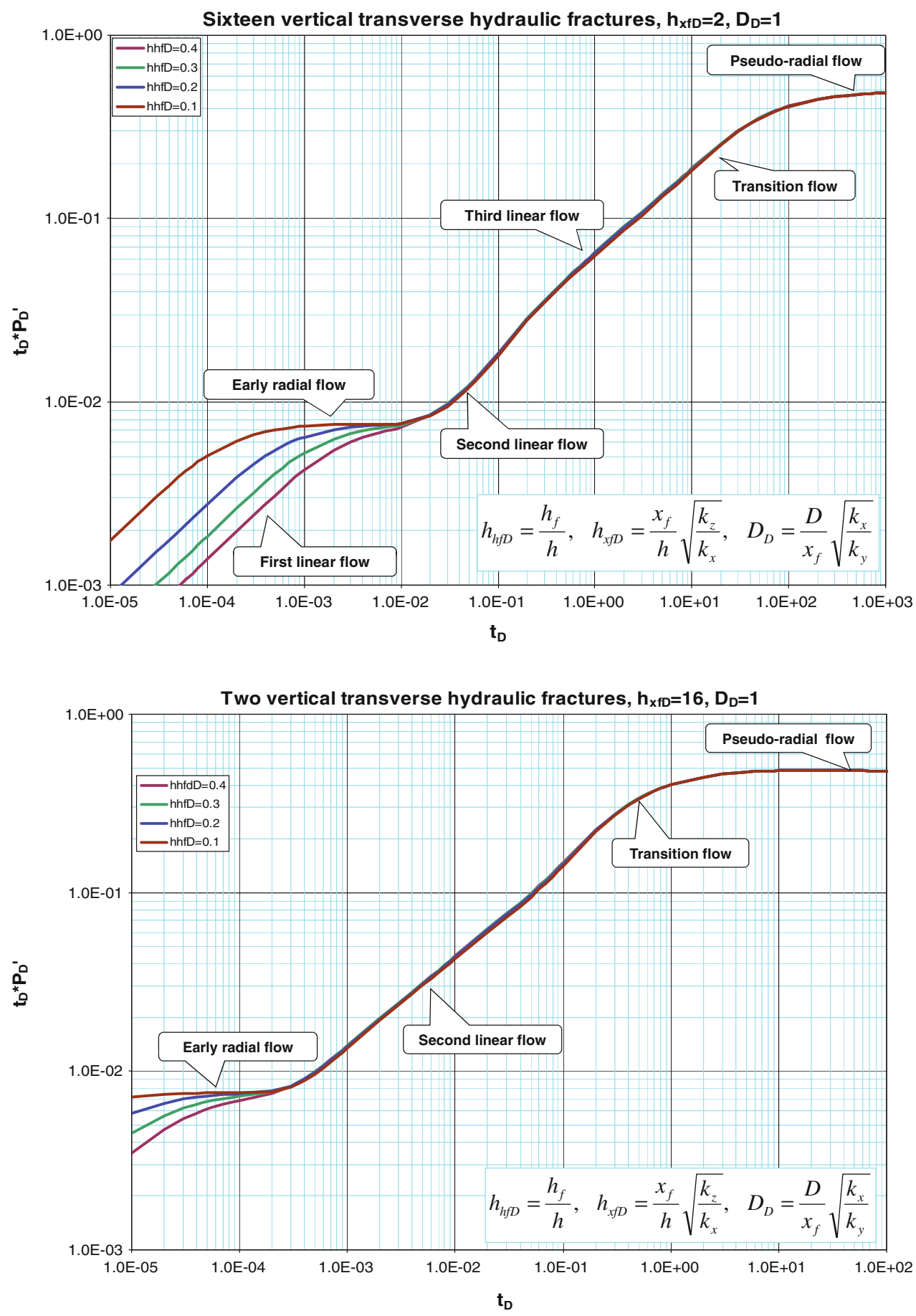

$\left(t_{\mathrm{D}} \times P_{\mathrm{D}}^{\prime}\right)_{\mathrm{ERF}}=\frac{0.5}{2 n h_{\mathrm{xfD}}}$.

Second linear flow regime

When the pressure pulse reaches the upper and lower boundary, reservoir fluid continues flowing linearly and directly from the formation to the fractures in the $X Z$ plane, especially for long spacing between fractures as shown in Fig. 30. The flow regime is represented by straight line with a slope of (0.5) in the log-log plots for pressure derivative with dimensionless time. The governing equation for a second linear flow regime in case of transverse hydraulic fractures is

$\left(t_{\mathrm{D}} \times P_{\mathrm{D}}^{\prime}\right)_{\mathrm{SLF}}=\frac{\sqrt{\pi t_{\mathrm{D}}}}{2 n}$. 
Fig. 27 Pressure behavior of sixteen partially penetrating hydraulic fractures

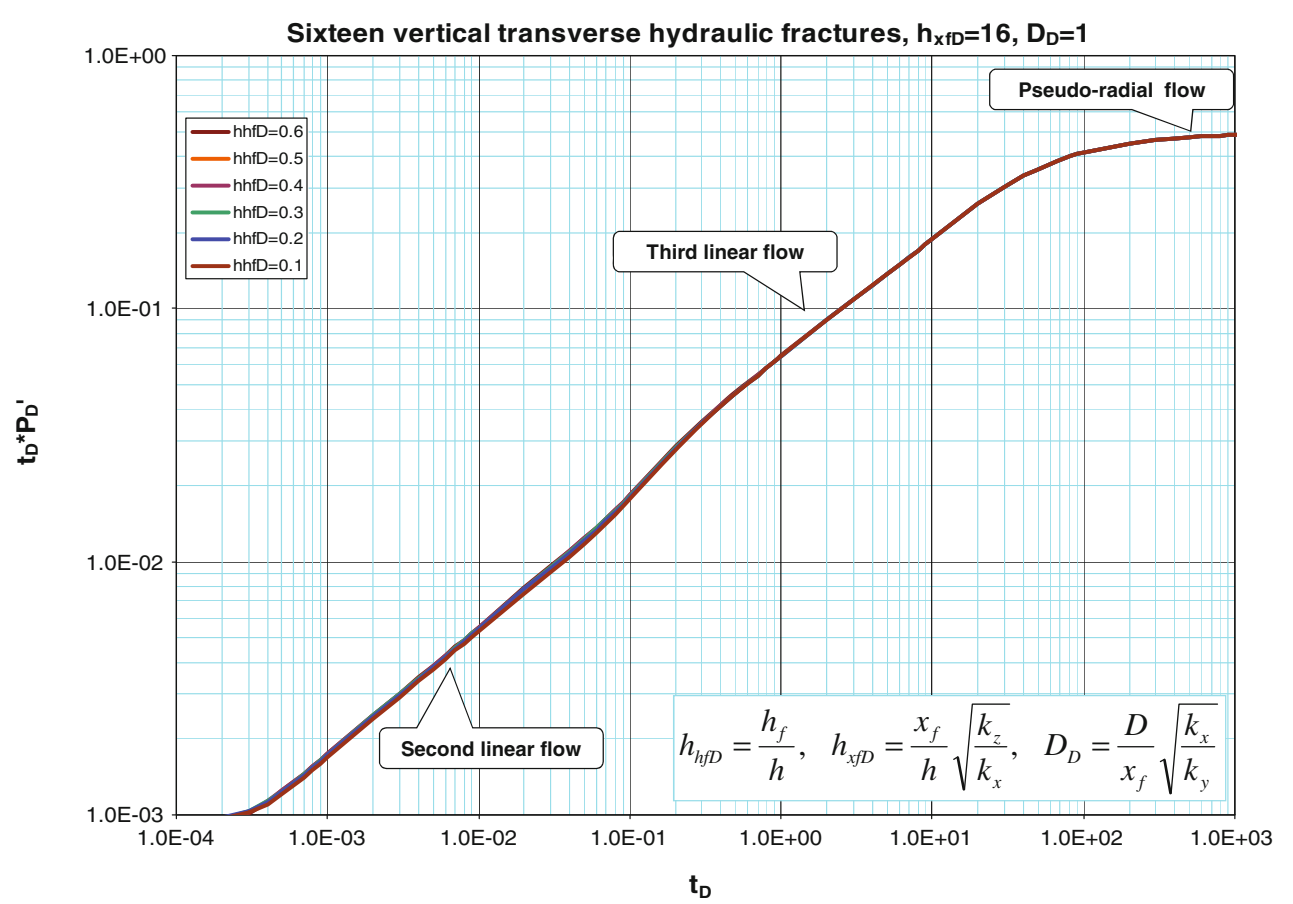

Fig. 28 Early (first) linear flow

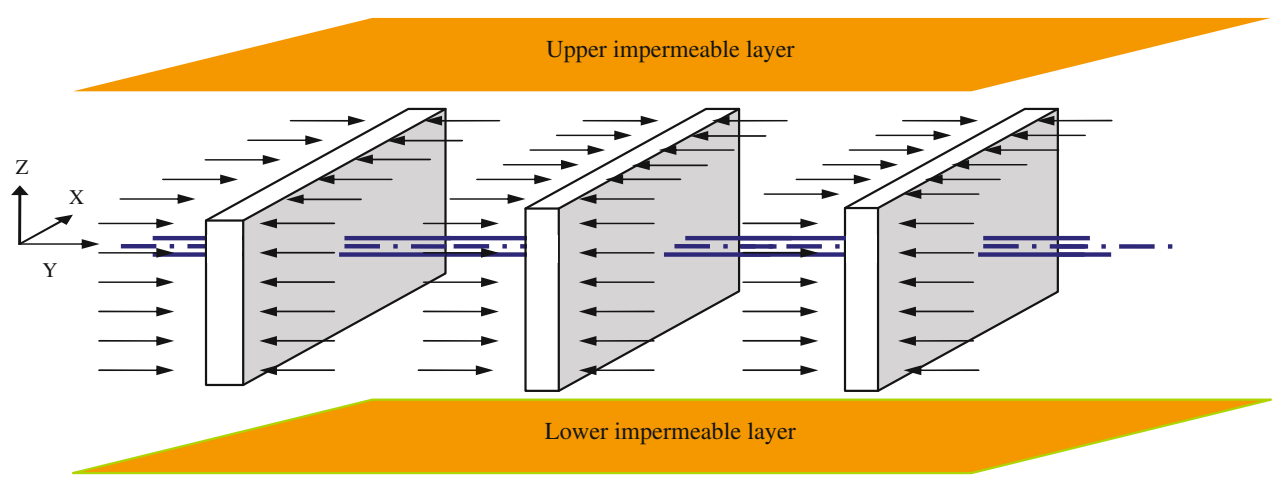

Third linear flow regime

A Third linear flow regime develops for short spacing, large number of hydraulic fractures, and large half fracture length. In this case, pressure behavior can be considered similar to the pressure behavior of long horizontal wells. The flow takes place in the $Y Z$ plane toward the fractures as shown in Fig. 31. This flow is represented by a straight line of a slope $(0.5)$ in the log-log plot of dimensionless pressure derivative with dimensionless time. The governing equations for a third linear flow regime are

$$
\begin{aligned}
& \left(P_{\mathrm{D}}\right)_{\mathrm{TLF}}=\frac{1.2 \sqrt{\pi t_{\mathrm{D}}}}{n D_{\mathrm{D}}}, \\
& \left(t_{\mathrm{D}} \times P_{\mathrm{D}}^{\prime}\right)_{\mathrm{TLF}}=\frac{1.2 \sqrt{\pi t_{\mathrm{D}}}}{2 n D_{\mathrm{D}}} .
\end{aligned}
$$

Intermediate radial flow regime

Intermediate radial flow regime develops for long spacing between fractures when there is sufficient time for reservoir fluid to flow radially in the $X Y$ plane to each individual fracture as shown in Fig. 32. The governing equation for this flow regime is

$\left(t_{\mathrm{D}} \times P_{\mathrm{D}}^{\prime}\right)_{\mathrm{IRF}}=\frac{0.5}{n}$.

\section{Pseudo-radial flow}

Pseudo-radial flow regime is the dominant flow for all cases at late time when reservoir fluids flow in the $X Y$ plane radially toward the fractures such as shown in Fig. 33. This flow is characterized by constant value (0.5) for the 
Fig. 29 Early radial flow regime

Fig. 30 Second linear flow regime

Fig. 31 Third linear flow regime

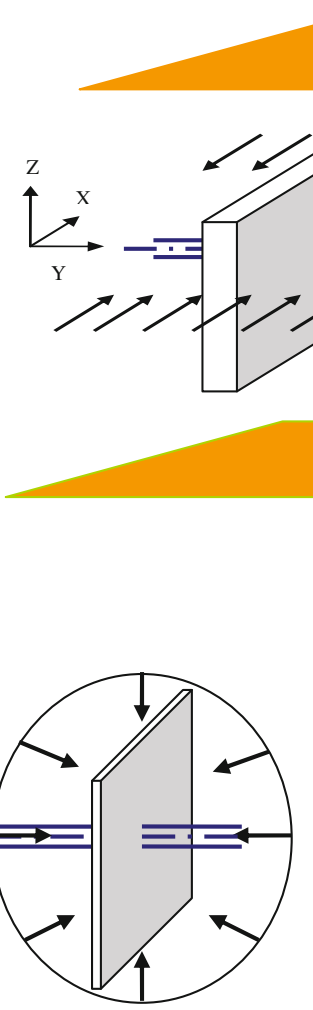

Fig. 32 Intermediate radial flow regime

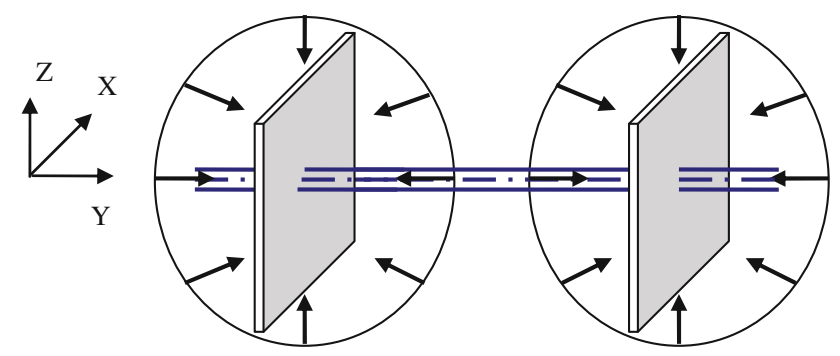

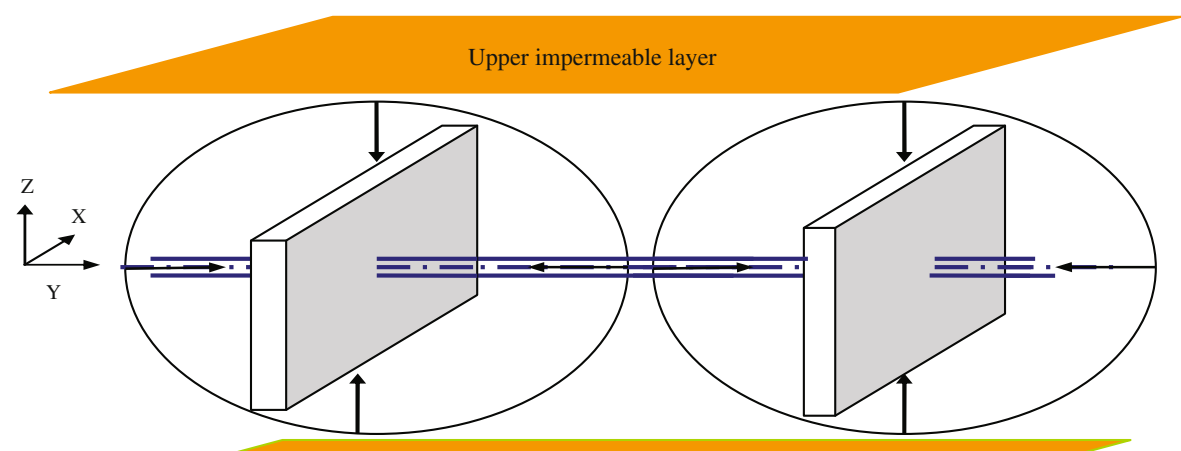

Lower impermeable layer
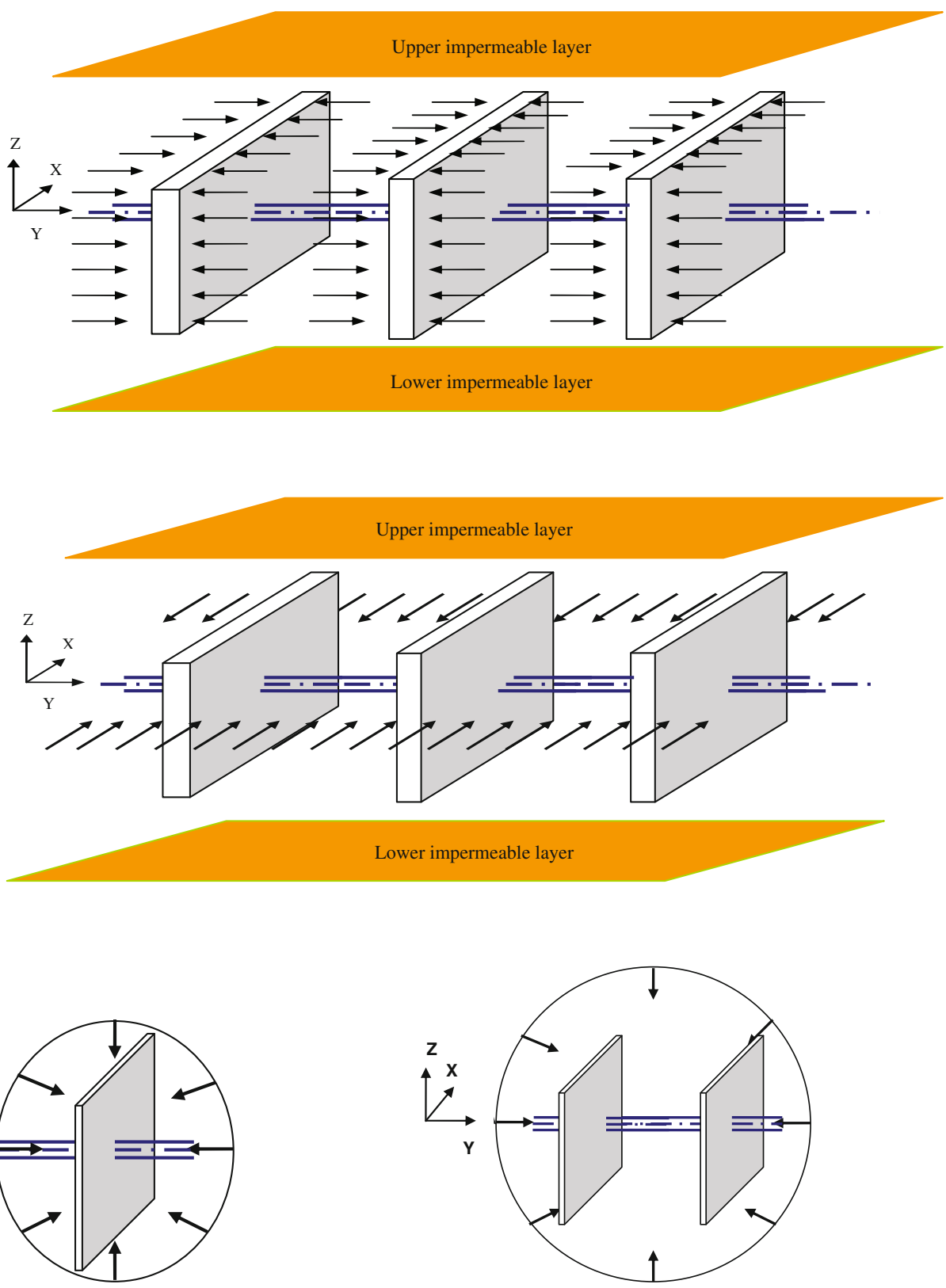

Fig. 33 Pseudo-radial flow regime 
Fig. 34 Channel flow regime

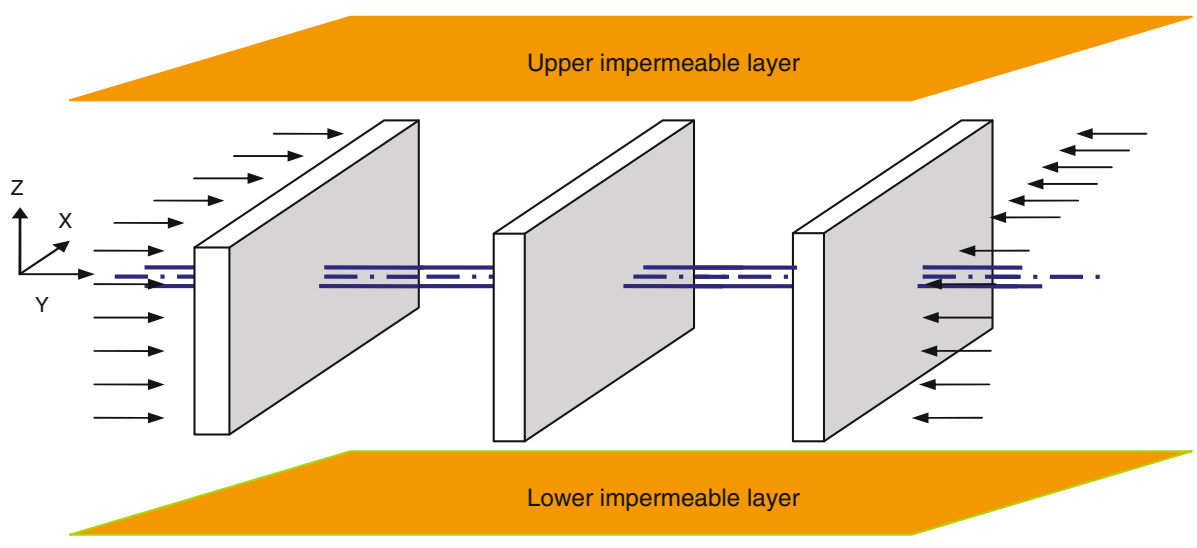

dimensionless pressure derivative curves on log-log plot of dimensionless pressure and dimensionless time. The governing equation for this flow is

$\left(t_{\mathrm{D}} \times P_{\mathrm{D}}^{\prime}\right)_{\mathrm{PRF}}=0.5$.

\section{Channel flow}

This flow starts when the pressure behavior is affected by the closest outer boundaries of the bounded reservoirs as shown in Fig. 34. It takes place for narrow and long reservoirs with long fracture length that reach the boundary parallel to the wellbore. Reservoir fluid in this case flows in one direction toward the outermost fractures only. It is characterized by a slope of (0.5) on the pressure derivative curve.

Pseudo-steady-state flow

For long producing times in closed reservoir, pseudosteady-state flow regime appears as a result of the pressure being influenced by all four closed boundaries at the same time. It is characterized by the unit-slope line on the pressure derivative curve. The equation of this straight line is $\left(t_{\mathrm{D}} \times P_{\mathrm{D}}^{\prime}\right)_{\mathrm{pss}}=2 \pi t_{\mathrm{DA}}$.

\section{Conclusions}

1. Pressure behaviors and flow regimes of hydraulically fractured horizontal wells are affected by different parameters such as: reservoir drainage area, fracture dimensions, and the penetration ratio either in the vertical direction or in the horizontal plane.

2. Reservoir boundaries have significant impact on late time pressure behaviors and flow regimes, i.e., pseudoradial flow and pseudo-steady-state flow regime.

3. The penetration ratio in the horizontal plane affects the late time pressure behaviors and flow regimes. It does not have effects on early linear flow regime.
4. The vertical penetration affects early time pressure behaviors and flow regimes only, i.e., early linear flow regimes.

5. Partial penetration in the vertical direction may develop the following new flow regimes: second linear, early radial, and third linear flow regime.

Open Access This article is distributed under the terms of the Creative Commons Attribution License which permits any use, distribution, and reproduction in any medium, provided the original author(s) and the source are credited.

\section{References}

Al Rbeawi S, Tiab D (2012) Effect of penetrating ratio on pressure behavior of horizontal wells with multiple-inclined hydraulic fractures. SPE 153788 presented at the SPE western regional meeting held in Bakersfield, 21-23 Mar. doi:10.2118/153788-PA

Al-Kobaisi M, Ozkan E (2004) A hybrid numerical analytical model of finite conductivity vertical fractures intercepted by a horizontal well. SPE 92040 presented at SPE international petroleum conference in Puebla, 8-9 Nov. doi:10.2118/92040-MS

Alpheus O, Tiab D (2008) Pressure transient analysis in partially penetrating infinite conductivity hydraulic fractures in naturally fractured reservoirs. SPE 116733 presented at the SPE annual technical conference and exhibition, Denver, 21-24 Sept. doi: 10.2118/116733-MS

Cinco-Ley H (1974) Unsteady-state pressure distribution created by a slanted well or a well with an inclined fracture. Ph.D. Dissertation, Stanford University, California

Cinco-Ley H, Samaniego VF (1981) Transient pressure analysis: finite conductivity fracture case versus damaged fracture case SPE 10179 presented at the 56th annual fall technical conference and exhibition, San Antonio, 5-7 Oct. doi:10.2118/10179-MS

Cinco-Ley H, Ramey HJ, Miller FG (1975) Unsteady-state pressure distribution created by a well with an inclined fracture. SPE 5591 presented at the 50th annual fall meeting, Dallas, 28 Sept-1 Oct. doi:10.2118/5591-MS

Dinh AV, Tiab D (2009a) Transient pressure analysis of a well with an inclined hydraulic fracture using Tiab's direct synthesis technique. SPE 120545 presented at SPE production and operation symposium held in Oklahoma City, 4-8 Apr. doi:10.2118/120545-MS

Dinh AV, Tiab D (2009b) Transient pressure analysis of a well with an inclined hydraulic fracture using type curve matching. SPE 
120540 presented at SPE production and operation symposium held in Oklahoma City, 4-8 Apr. doi:10.2118/120540-MS

Gringarten AC, Ramey HJ (1973) The use of source and Green's function in solving unsteady-flow problem in reservoir. SPE J:285-296 (SPE 3818). doi:10.2118/3818-PA

Ozkan E (1988) Performance of horizontal wells, Ph.D. Dissertation, The University of Tulsa, Tulsa

Raghavan R, Uraiet A, Thomas G (1978). Vertical fracture height: effect on transient flow behavior. SPE J:268-277 (SPE 6016). doi:10.2118/6016-MS

Raghavan R, Chin-Cheng C, Bijin A (1997). An analysis of horizontal wells intercepted by multiple fractures. SPE J (SPE 27652). doi: 10.2118/27652-PA

Rodriguez F, Horne R, Cinco-Ley H (1984a) Partially penetrating fractures: pressure transient analysis of an infinite conductivity fracture. SPE 12743 presented at the SPE California regional meeting, Long Beach, 11-13 Apr. doi:10.2118/12743-MS
Rodriguez F, Horne R, Cinco-Ley H (1984b). Partially penetrating fractures: pressure transient analysis of a finite conductivity fracture. SPE 13057 presented at the 59th SPE annual technical conference and exhibition, Houston, 16-19 Sept. doi:10.2118/13057-MS

Wright CA, Conant RA (1995) Hydraulic fracture reorientation in primary and secondary recovery from low permeability reservoirs. SPE 30484 presented at the SPE annual technical conference, Dallas, 22-25 Oct. doi:10.2118/30484-MS

Zerzar A, Bettam Y, Tiab D (2003) Interpretation of multiple hydraulically fractured horizontal wells in closed systems. SPE 84888 presented at SPE international improved oil recovery conference in Asia Pacific, Kuala Lumpur, 20-21 Oct. doi: 10.2118/ 84888-MS 